\title{
Communicating environmental geoscience - An international survey
}

\author{
${ }^{1}$ Mines Branch, Department of Natural Resources, Government of Newfoundland and Labrador, PO Box 8700, St. John's, NL A1B 4J6, \\ Canada. E-mail: dliverman@gov.nl.ca \\ ${ }^{2}$ T\&D Operations \& Engineering BC Hydro, 333 Dunsmuir Street, 13th, Vancouver, BC, V6B 5R3, Canada. \\ E-mail: monica.jaramillo@bchydro.com
}

\begin{abstract}
Communication is a major barrier in using the results of environmental geoscience to inform public debate and policy. The results of an international survey of environmental geoscientists on communication issues are discussed. The results suggest that environmental geoscientists recognize that communicating with media and public is important. They believe that their research is not too complex or difficult for the public to understand, and they generally feel well equipped to engage the public. Few of them, however, are trained in this area, and most are interested in taking courses to improve their skills. Their research is important in developing policy but often they find it challenging to communicate with policy makers and politicians. Thus their research is not always used effectively in developing policy.
\end{abstract}

\section{Introduction}

Geologists whose research deals with environmental problems such as landslides, floods, earthquakes, and other natural hazards that affect people's health and safety must communicate their results effectively to the public, policy makers and politicians. There are many examples of geological studies being ignored in policy and public action; this may be due in part to problems and barriers associated with communication.

The International Union of Geological Sciences Commission for "Geoscience for Environmental Management" established a working group to deal with the issue of communicating environmental geoscience. This group is holding workshops, publishing collections of papers (Liverman et al., 2008), and is looking at other means to aid geoscientists in addressing these problems.

One task the working group set itself was examining environmental geoscientists attitudes and experiences of communicating environmental geoscience. In order to do this an on-line survey was created. Previous studies of scientists and their attitudes towards and experiences of communication were restricted to specific countries. These studies also considered the full range of science, rather than the specific discipline of environmental geoscience. There is thus a need to consider the broader international scene, and to examine whether environmental geoscientists face any particular challenges in the area of communication not identified by these previous studies.

\section{Previous work}

Early surveys examining communication and scientists were specific to the USA (Harz and Chappell, 1998) and United Kingdom (Royal Society, 2006); and were generalized to include all scientists. Peters et al. (2008) surveyed stem cell researchers and epidemiologists in five leading research countries on media relationships.

The study of Harz and Chappell (1998) focused on the relationship between science and the media, and surveyed both scientists and journalists. Their wide-ranging report emphasized the serious gulf between media and science, and identified this as a critical problem for the future as in an increasingly technological society, the media form the most important means of informing the public about science. Together with numerous recommendations they suggest that

- Scientists and journalists should begin a dialogue to educate each other about the ways in which their needs and the needs of the public can be met.

- The scientific community should train communicators to speak for different scientific disciplines.

- Publishers of scientific papers should require authors to include summaries of their findings - written in plain language - that put the work in perspective and explain its relevance and importance.

The Royal Society study was designed to examine the attitudes and activities of scientists and engineers towards engaging and communicating with the public. This involved a survey of nearly 1500 scientists. The authors noted an increase in public engagement over the six year period since a previous similar survey but were concerned that "that many scientists see the main reason for engaging with the public as the need to 'educate' them rather than to debate, listen and learn as part of a genuine dialogue."

A number of recommendations were made including:

- More young scientists should be encouraged to be involved in public engagement activities.

- Institutions and funding bodies need to provide better support for scientists undertaking public engagement.

- There should be greater rewards and recognition for public engagement work.

- There should be better coordination between organizations working on public engagement. 
Peters et al. (2008) sampled a sub-set of the scientific community in the UK, USA, France, Japan and Germany, and identified that media contacts of scientists in those countries were more frequent and positive than many had reported previously. They also suggested that scientists involved in interactions with the media tended to be highly productive, and be leaders in the scientific community.

The general issues associated with environmental geoscience and communication have been explored by the papers collected in Liverman, Pereira and Marker (2008). Boykoff (2008) suggested that the challenges of communicating climate change science in the midst of a heated debate acted to discourage many scientists from engaging the media. This unwillingness was often based on experience of having research misinterpreted, selectively used, or quoted to advance policy or political objectives. Boykoff goes on to state "the 'battlefield' of communicating and understanding environmental geoscience is not well-served by scientists reluctant to acknowledge and act on what is an integral piece of one's contemporary responsibility: interacting with mass media". Nield (2008) outlined common misconceptions of the way the media operates, emphasizing the need for scientists to understand how journalists work, and the driving forces behind the media business in order to be effective.

Liverman (2010) provided an overview of communication issues relating to geological hazards, and concluded that despite many advances in the field of communication of science, and some admirable efforts in the communication of geohazards, much needs to be done. It is clear that geoscience research with direct implications to health, safety and economic well-being is frequently not being used by the public, policy makers and politicians.

Liverman $(2008,2010)$ suggested that environmental geoscientists needed to improve communication skills and be provided with training. However these suggestions were based largely on general studies of science communication rather than any detailed survey of environmental geoscientists.

\section{Methods}

\section{Survey design}

The survey consisted of thirty-nine questions, divided into broad areas. Ten questions dealt with the background and demographics of the respondent, seven focused on dealings with the media, seventeen on public engagement, and four on policy implications. Most of these questions were in a multiple choice format. There was also an opportunity to provide general comments in open ended questions. The survey was developed in English, but a Spanish version was also available as an option.

The complete survey is available on the Geoscience for Environmental Management web site at http://communication.iugs-gem.org/

Many of the questions used in the survey were similar to those posed in the studies by Hartz and Chappell (1998) and the Royal Society (2006). This allowed a comparison of the responses of environmental geoscientists with those of the larger population of scientists.

\section{Distribution}

The major challenge of the study was encouraging a wide spectrum of geoscientists to complete the survey. It was not possible to develop a rigorous method to sample the entire population of global environmental geoscientists. The effort in identifying this population, and then contacting selected sample groups would be immense, and in some cases nearly impossible to accomplish. Most countries do not maintain a publically accessible register of geoscientists as a whole, let alone a sub-group of environmental geoscientists. It was thus decided to work within the limitations imposed and attempt to contact as many environmental geoscientists as possible using the networks available to us. The most powerful of these was that of the International Union of Geological Sciences. Two main means were used here. The survey is a product of the IUGS Geoscience for Environmental Management Commission working group on "Communicating Environmental Geoscience". All members of the working group, and all officers of the commission were contacted and asked to distribute information about the survey to all environmental geoscientists within their contact groups. The Commission itself is designed to have a wide geographical representation, with officers representing Europe, China, North America, South America, Russia, Japan, India and Africa, along with working group chairs. These officers represent experienced, knowledgeable and influential scientists within their geographical regions, with excellent connections.

In addition the newsletter of the International Union of Geological Sciences carried a short article about the survey. This has a global distribution estimated at between 10-12,000 geoscientists. National organizations focusing on environmental geoscience were contacted, and asked to place information about the survey in their newsletters, or distribute the information electronically. Various e-mail distribution lists were also used to publicise the survey.

The survey was conducted entirely on-line, using a commercial web-based survey company. This allowed for rapid and easy distribution of the survey to a wide range of potential participants, as well as providing a convenient means of analyzing responses.

\section{Results}

\section{Response rate}

The survey was on-line from August 2009 to July 2010. There were 142 responses in all, with 29 to the Spanish language version. 128 respondents completed the entire survey.

There were responses from 48 countries, with 26 countries represented by a single response (Fig. 1). The highest number of response was from Canada (13), and then Germany (10).

Overall the response rate was disappointing and makes interpretation of the results challenging. A larger sample size would allow more certainty in interpretation of the results. The choice of those contacted with regard to the survey was also highly selective, and thus results should not be viewed as accurately reflecting the opinions of environmental geoscientists as a whole. However, the geographical range, high level of training, years of experience in the field, and status of these respondents within their profession indicates that the opinions outlined here have considerable weight, and may be considered to provide important direction in the area of study.

Translations into other languages may have helped to obtain a broader response rate.

For comparison, the Royal Society survey (Royal Society 2006) cited above had 1485 respondents (52\% response rate); and that of Hartz and Chappell (1998) 1432 respondents of which 670 were scientists (of 2002 scientists surveyed). 


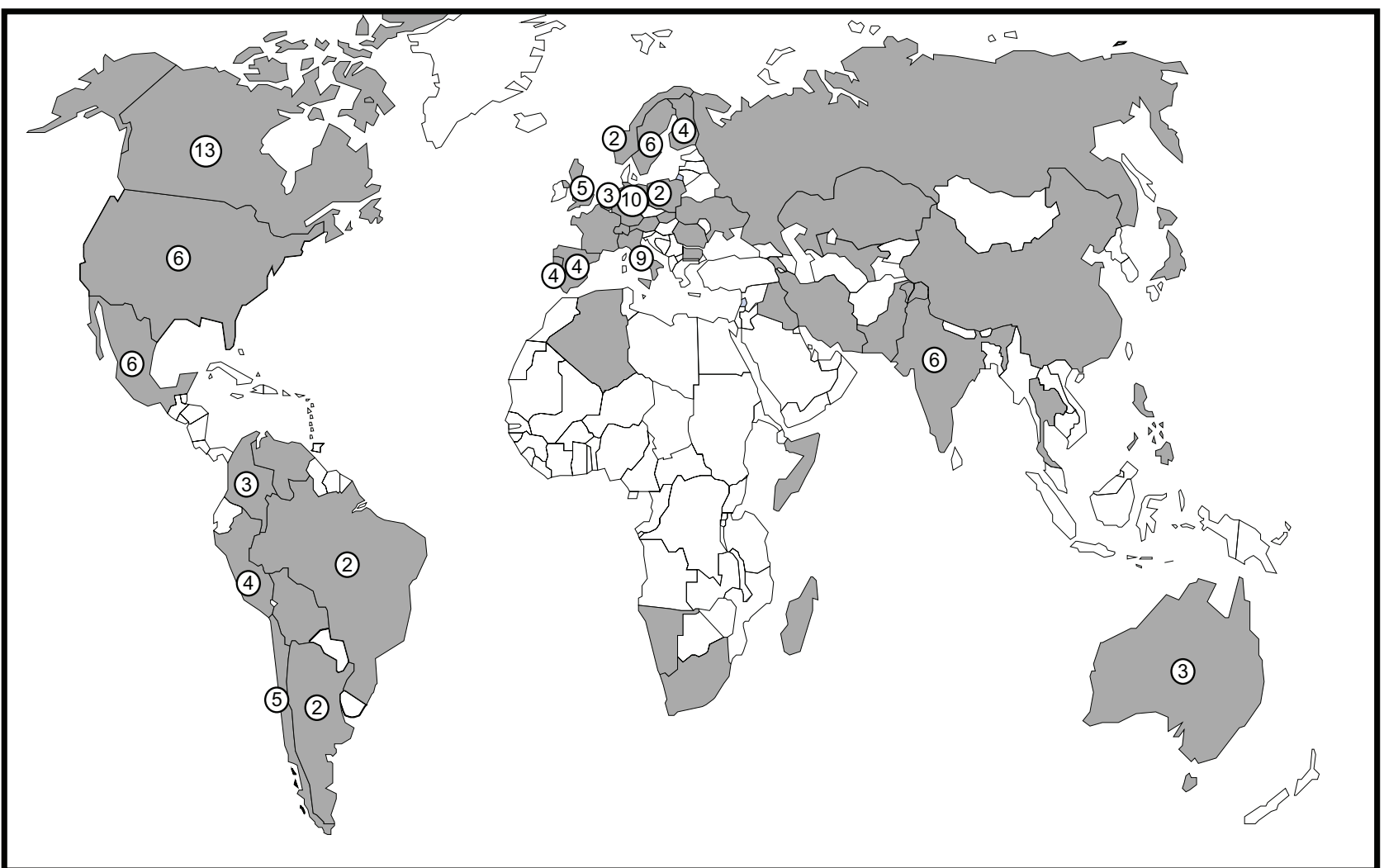

Figure 1. Geographic distribution of responses; all countries that provided a response are shaded grey; circled numbers indicate number of responses if greater than 1 .

\section{Demographics}

Respondents were dominantly male $(69 \%)$, older $(75 \%$ over 40 , $40 \%$ over 50 ), and with advanced degrees (89\% Masters or Doctorate) (Fig. 2). The gender distribution and education level perhaps reflects the overall demographics of older geoscientists. The relatively low response rate from younger geoscientists (only four less than 30 years

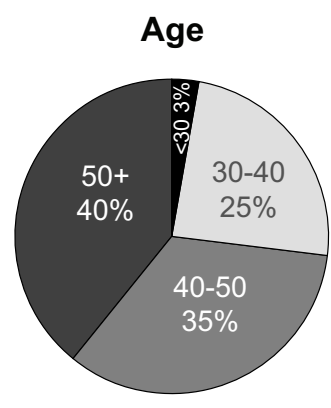

Experience (years)
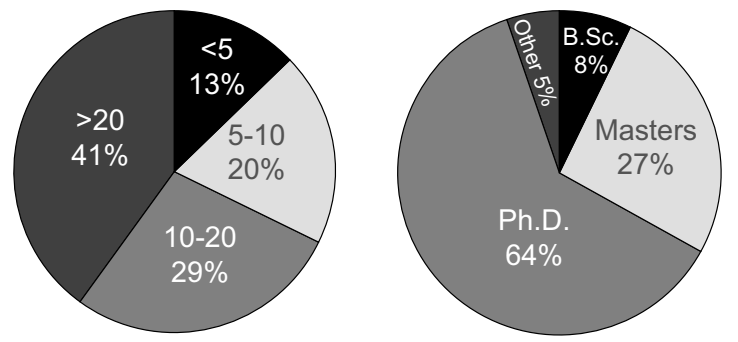

Figure 2. Demographics of respondents. old) is interesting. Although no firm data exists, it is likely that the responses do not reflect the overall age distribution of environmental geoscientists, but perhaps indicates biases in responses caused by the method of distributing the survey. It might also indicate that communication issues become more relevant to environmental geoscientists later in their careers; or that less experienced geoscientists felt they lacked the background to complete the survey.

For comparison with the profile of survey respondents, women represented $43 \%$ of geoscience graduates in the USA in 2009, and $29 \%$ of those employed in geoscience and environmental geoscience (American Geological Institute, 2010). Although global in scope, the respondents in this survey seem to follow a similar pattern.

Respondents identified diverse areas of research, as might be expected given the broad spectrum of environmental geoscience. Natural hazards were a major focus, along with hydrogeology, engineering geology, land-use planning and geochemistry. 19 respondents indicated research interests in the social science of hazards, 20 in science communication, and 19 in policy.

Over half the respondents were employed by government, with $28 \%$ in universities, and a much smaller number employed by industry or as consultants. $41 \%$ had been working in the field for over 20 years, with $29 \%$ between 10 and 20 years, indicating considerable experience overall.

\section{Media}

Environmental geoscience is often the focus of media interest, as the implications of research in this area often directly affect people and communities. $62 \%$ of respondents indicated that their work had 
been reported in the media in the previous 12 months (several times in $31 \%$ of cases). Only $21 \%$ of those whose work had been reported were dissatisfied with the coverage, yet $52 \%$ felt that the scientific understanding of the journalists who covered the work was inadequate.

Respondents were asked whether they agreed or disagreed with a series of statements regarding scientists and the media (Fig. 3). These statements were a sub-set of those used in the more extensive survey of Hartz and Chappell (1998). For the most part, the responses in this survey are similar to those recorded by Hartz and Chappell (1998). Environmental geoscientists believe that their subject is not too complex to be covered by mainstream media, but identify some major issues in this media coverage. One question where there was a significant diversion from the Hartz and Chappell survey was in regard to interest in negative stories. $72 \%$ of respondents agreed that the media is more interested in negative stories about environmental geoscience than positive stories - as opposed to 36\% in the 1996 survey. The question was not specific as to whether the stories had negative implications for society, or whether science was portrayed in a negative light. It is likely however that this is due mainly to the nature of environmental geoscience, and the subject areas coverednatural hazards, environmental geochemistry, hydrogeology etc.

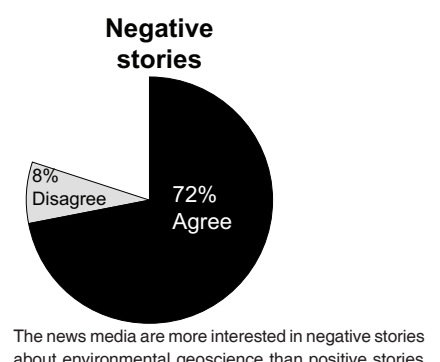

about environmental geoscience than positive stories Understanding

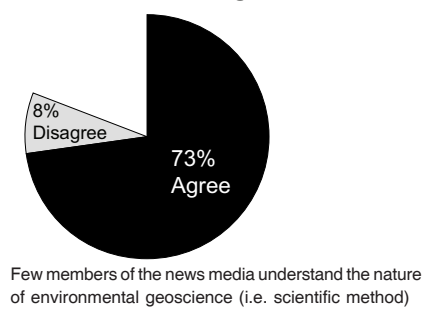

Error-prone?

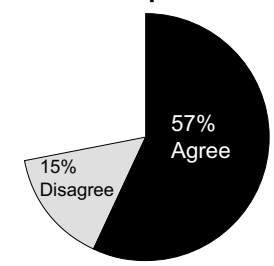

Members of the news media rarely get details about environmental geoscience correct.

Probability

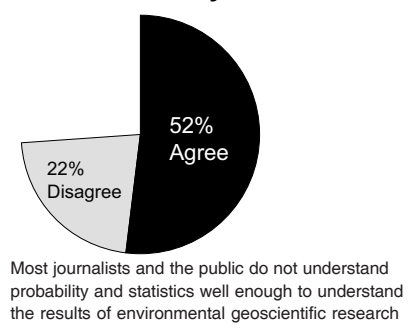

Figure 3. Opinions on media issues.
Coverage of natural hazards tends to be of disasters with loss of property and life, and generally the more positive aspects of research in environmental geoscience are not as newsworthy.

The other question where there was a significant divergence dealt with statistics and probability. 52\% of respondents agreed that journalists and the public did not understand probability and statistics well enough to understand the results of scientific research- Hartz and Chappell reported $82 \%$ agreed with this statement. The corresponding numbers disagreeing were $22 \%$ (this survey) and $6 \%$ (Hartz and Chappell 1998). This difference is particularly surprising given the importance of probability and risk in conveying the results of hazard related research to the public and media.

$61 \%$ of the respondents identified scientific language and use of jargon as a major problem in communication (50\% in Hartz and Chappell, 1998). This is a positive outcome - if scientists are aware that their own use of language represents a challenge to communication, then they can endeavour to remove that barrier.

\section{Education and training}

Conventional geoscience education prepares scientists poorly for communication with media and public. Only $15 \%$ of respondents had courses in communication as part of their education, and $26 \%$ had some training in dealing with the media (Fig. 4). Most courses in geoscience communication offered at universities focus on scientific communication- how to present a paper, write an abstract, prepare a poster etc. Thus most environmental geoscientists have little training in dealing with the media or public, and most are thus self-taught, improving through personal experience. This is not due to lack of interest in the area- $72 \%$ of respondents were willing to take courses to help them deal with the media.

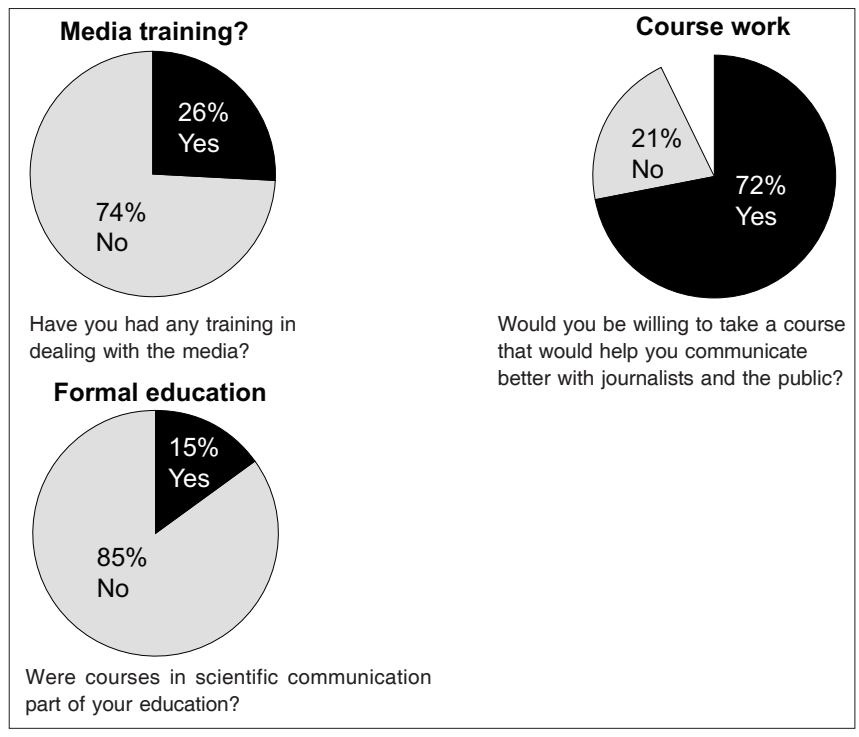

Figure 4. Education questions.

\section{Public engagement}

Respondents were asked whether they agreed or disagreed with a series of statements regarding public engagement (Fig.5). The responses show a strong interest in communicating science to the public. $78 \%$ agreed that scientists have a moral duty to engage with the non-specialist public, and $70 \%$ agreed that such engagement is personally rewarding. $79 \%$ disagreed with the statement that their 


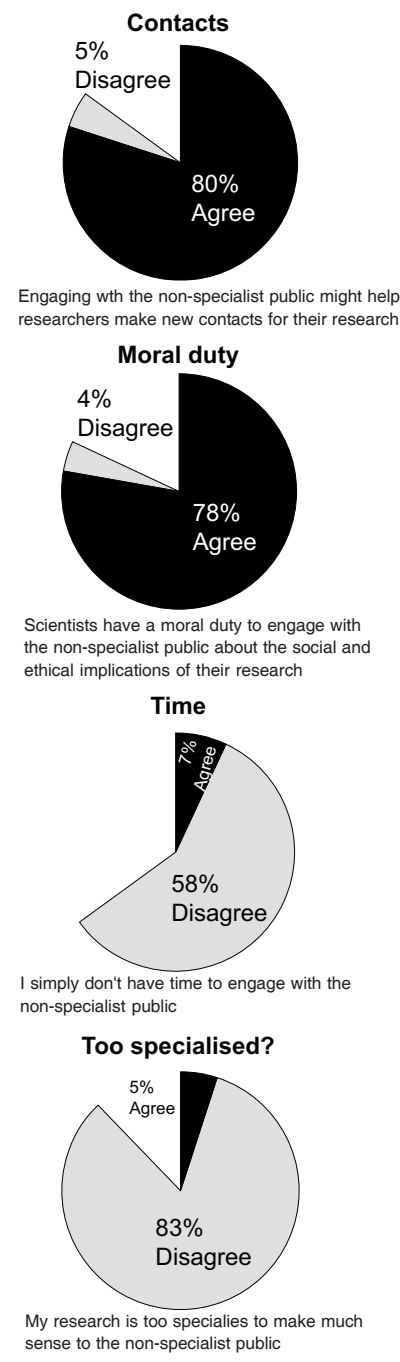

Figure 5: Public engagement issues

research would not be of public interest, and $83 \%$ did not think that their research was too specialized to make sense to the public. The Royal Society study (Royal Society 2006) asked similar questions, and found that $36 \%$ agreed with the statement "I just don't have time to engage with the non-specialist public". This study showed only $7 \%$ agreement with the statement, with $58 \%$ disagreeing.

Only $14 \%$ of respondents had any training in dealing with the non-specialist public, yet $73 \%$ felt they were fairly well equipped or well equipped for the task - an interesting contrast. $73 \%$ felt their employer was supportive of public engagement and $67 \%$ felt colleagues were supportive of such efforts. $76 \%$ felt it was important to engage the public as part of their job.

Thus there are many positive indicators for successful public engagement resulting from the survey. When asked how frequently they actually engaged with the public a different picture emerged. Respondents were asked how many times they had taken part in each of a list of activities. Many had not taken part in any of those listed (Table 1). Public lectures were the most common form of engagement with $76 \%$ giving at least one during the year, and $72 \%$ had engaged with policy-makers. However only 58\% had taken part in public dialogues or debates, and even fewer had been interviewed by the media, worked with science centres or been involved in science fairs. $43 \%$ indicated they would like to spend more time on public engagement.
Table 1. Thinking about public engagement with, and communication about, science, roughly how often in the past 12 months have you done each of the following?

\begin{tabular}{|l|c|c|c|c|}
\hline & Frequently & $\begin{array}{c}\text { Several } \\
\text { times }\end{array}$ & $\begin{array}{c}\text { Once or } \\
\text { twice }\end{array}$ & $\begin{array}{c}\text { Not at } \\
\text { all }\end{array}$ \\
\hline Given a public lecture & 11 & 23 & 42 & 24 \\
\hline Engaged with policy- makers & 11 & 24 & 36 & 28 \\
\hline Worked with teachers/schools & 9 & 17 & 42 & 32 \\
\hline $\begin{array}{l}\text { Engaged with Non-Governmental } \\
\text { Organisations }\end{array}$ & 13 & 19 & 33 & 35 \\
\hline Written for the non-specialist public & 6 & 19 & 35 & 40 \\
\hline $\begin{array}{l}\text { Participated in an institutional open } \\
\text { day }\end{array}$ & 7 & 12 & 39 & 42 \\
\hline $\begin{array}{l}\text { Taken part in a public dialogue } \\
\text { event/debate }\end{array}$ & 6 & 18 & 34 & 42 \\
\hline $\begin{array}{l}\text { Been interviewed by a newspaper } \\
\text { journalist }\end{array}$ & 2 & 15 & 40 & 44 \\
\hline Worked with science centres/museums & 5 & 15 & 30 & 51 \\
\hline Been interviewed on radio & 4 & 10 & 24 & 61 \\
\hline Judged competitions & 2 & 5 & 21 & 73 \\
\hline
\end{tabular}

The current survey however clearly shows that environmental geoscientists are far more involved in public engagement than the more general group of scientists surveyed by the Royal Society (2006). Of this list of activities given in Table 2, the majority of respondents in the Royal Society Survey answered that they did not take part in them at all. The "not at all" response rate ranged from $89 \%$ (judged competitions) to $60 \%$ (public lecture), with the exception that $56 \%$ had participated in an institutional open day. This is in contrast to this survey with a range of $73 \%$ (judged competitions) to $24 \%$ (public lectures).

The "public" consists of many groups, each with different interests (Table 2). When asked about the importance of engaging with various groups, fellow scientists were rated highest, with $94 \%$ indicating it was important to directly engage them. However the next highest group was policy makers $(80 \%)$, indicating perhaps a desire to influence policy, followed by the general public (76\%), schools (73\%), and politicians $(69 \%)$. There was less interest in engaging social scientists (65\%) and non-governmental organizations (63\%).

When asked which groups it was easiest and most difficult to talk to, it was not surprising that most environmental geoscientists find it easiest to engage with other scientists (Fig. 6). Politicians were identified as representing the greatest challenges in engagement (49\%), followed by policy makers $(15 \%)$.

Table 2. How important do you feel it is that you personally, in your current post, directly engage with each of the following groups about your research?

\begin{tabular}{lcc}
\hline Group & Important & $\begin{array}{c}\text { Not important or } \\
\text { not required }\end{array}$ \\
\hline $\begin{array}{l}\text { Scientists within discipline } \\
\text { Scientists and engineers }\end{array}$ & $94 \%$ & $0 \%$ \\
outside of discipline & $84 \%$ & $1 \%$ \\
General public & $76 \%$ & $9 \%$ \\
Politicians & $69 \%$ & $10 \%$ \\
Policy makers & $80 \%$ & $9 \%$ \\
NGOs & $63 \%$ & $11 \%$ \\
Schools & $73 \%$ & $8 \%$ \\
Social scientists & $65 \%$ & $9 \%$ \\
\hline
\end{tabular}




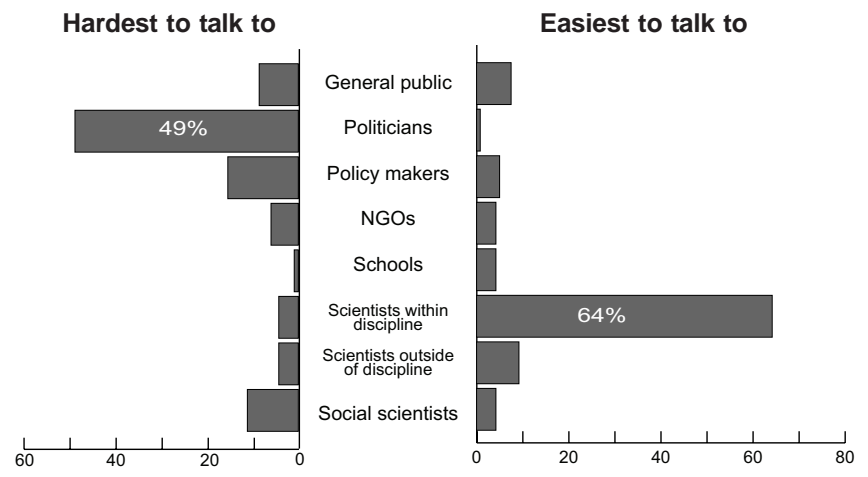

Figure 6. Which groups are hardest/easiest to talk to?

When asked to identify barriers to public engagement, $49 \%$ identified the main single barrier as being that of time constraints and priorities. The solution proposed by many was assistance in terms of funding (77\% agreed that funders of research should help scientists communicate with the public); institutional support, training and skill development, and time specifically allocated to this area as part of their job.

\section{Policy}

When asked "Do you think your work has implications for society and/or policy-makers and regulators" $95 \%$ answered that their research had at least some implications, with $63 \%$ indicating it had major implications. However $41 \%$ had only rarely or never been consulted in developing policy, although $31 \%$ were frequently involved in policy development. Of those whose research had been used in development of policy, $25 \%$ felt they had been ineffective, $64 \%$ somewhat effective and only $11 \%$ very effective. This perhaps reflects the suggestion that the most challenging groups to engage with are politicians and policy makers.

When asked to identify the barriers preventing science informing policy, the two most common were the short-term focus of policy, and the lack of scientific background of policy makers; with lack of access to policy makers also being significant.

\section{Other comments}

Some interesting comments were provided outside of the formal questions. One stated

"I think this survey is not cognizant of the real decision-makers in our society: industry lobbyists who have the ears of both state and federal legislators. Banking, equity, insurance, and related industries have a large presence - almost a control - in and around legislative chambers (at least in the US). If geoscientists can communicate with these groups, and convince them that geoscience-wise policies make business sense, then policies may change... Proactive outreach to key industry groups is absolutely imperative."

Another comment related to the skills required by consultants.

"Consultants always communicating; by necessity to make a living! Mainly dealing with regulators and, as required, as expert witnesses in litigation, which inherently requires communicating complex material in a manner presumably understandable to a judge or lay jury."

These are valid points and any follow-up survey might aim to accommodate these in the question design.

\section{Conclusions and recommendations}

It is interesting to compare the results of this survey with the main two studies preceding it- Hartz and Chappell (1998) and Royal Society (2006). These studies were limited in their geographical scope but broader in their population surveyed. It might be expected that there have been changes in the scientific community since 1998 . Generally however, the results of this survey do not differ significantly from those obtained in these other studies. This suggests that communications issues are viewed in a similar manner by scientists throughout the world, and that environmental geoscientists do not differ significantly from the scientific community as a whole when looking at communication of science.

The areas of difference are highlighted in the discussion above and in part can be explained by the nature of environmental geoscience. It does for instance tend to attract news stories emphasizing the negative aspects of geoscience - natural disasters and environmental problems.

What stands out from the survey, however is the interest in public engagement shown by environmental geoscientists. This is perhaps because it of all the areas of geoscience has the greatest direct impact on the public and communities - although mining and petroleum geoscience are essential for modern society, the science associated with them is one step removed from the public. One respondent commented "I work with geohazards and found not important but essential to co-involve the general public in disaster risk reduction efforts."

Even given the limitations of this survey, it seems that environmental geoscientists spend more time in public engagement activities than most other scientists, when compared to the Royal Society (2006) survey.

However when asked specifically how much public engagement they were doing, it was clear that this was, by their own standards, less than ideal.

To summarise, environmental geoscientists recognize that communicating with media and public is important, they believe that their research is not too complex or difficult for the public to understand, and they generally feel well equipped to engage the public. Few of them, however, are trained in this area, and most are interested in taking courses to improve their skills. Their research is important in developing policy but often they find it challenging to communicate with policy makers and politicians. Thus their research is not always used effectively in developing policy.

The lack of access to politicians and policy-makers is sometimes due to institutional structure - scientists working within governments are constrained in the manner in which they interact with these groups. In other cases scientists are unaware of how to reach this audience; the problem is compounded when there is less importance placed on interaction with social scientists and NGOs. These groups often are much more aware of how to interact with policy makers and politicians and may form useful allies in communicating science to this audience.

Barriers to communication are clearly identified in the survey, with the most prominent being those of time and funding constraints.

Thus communication of environmental geoscience is an important issue for its practitioners. The respondents were mostly scientists in the latter part of their careers and their advice in removing barriers to communication is likely based on extensive experience. Some basic recommendations can be derived from the survey. 
Firstly training and education in communication is currently inadequate. It is important that universities incorporate training in media relations and public engagement in their geoscience curriculums, as well as training in scientific communication. Institutions should also assist their employees by providing support and training in these areas.

Secondly, media relations and public engagement need to be considered in project development and funding. Funding agencies supporting environmental geoscience need to ensure that public engagement is an integral part of the project, and that adequate resources are available to make such engagement effective. Employers should encourage public engagement through ensuring that support is given to public engagement activities.

The survey respondents identified that the main barrier to the effective use of science in policy was the lack of scientific background of policy-makers. The corollary, perhaps, is that environmental geoscientists do not understand the process of developing policy, and thus have difficulty tailoring their communication to the background of policy makers. One respondent commented "Policy makers use other time scales than researchers. They have a more short-term view. The work of communicating science needs to be repeated again and again." This type of understanding of the process of policy development can only help scientists to ensure their science is used effectively.

Due to the relatively small number of respondents, and somewhat haphazard means of sampling the population of environmental geoscientists, these conclusions should be viewed as tentative, and there is considerable speculation involved when providing explanations of trends. This study may provide the foundation for a more comprehensive and carefully designed survey with a more accurate sampling method. It is clear, however, that environmental geoscientists are interested in communication issues, partake in public engagement, and are aware of problems associated with communication. A more comprehensive survey is not needed to address the major problems identified - simply action from those in a position to take it.

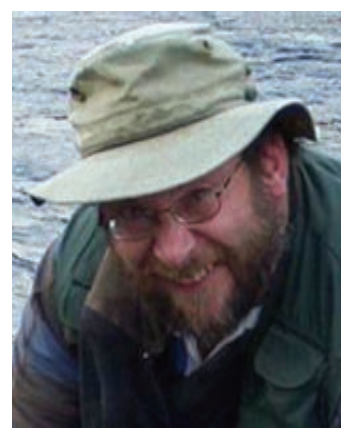

David Liverman was born in Accra, Ghana and grew up in the UK. He completed his undergraduate degree in geology at Edinburgh University, and subsequently moved to Canada where he acquired M.Sc and Ph.D. degrees from the University of Alberta. He is an officer of the IUGS Commission "Geoscience for Environmental Management" and heads the Commission's working group on communicating environmental geoscience. His research interests include Quaternary geology, natural hazards, and geoscience communication.

\section{Acknowledgements}

We thank all respondents of the survey for their assistance; the IUGS Commission "Geoscience for Environmental Management" for their support; Dra. Dolores Pereira, Depto. Geología, Facultad de Ciencias, Universidad de Salamanca for assistance with the Spanish survey; Iain Stewart (University of Plymouth) for his comments and input; and the members of the Communicating Environmental Geoscience Working Group. Reviews by Brian Marker and Tony Berger helped substantially improve the paper.

\section{References}

American Geological Institute, 2010, Participation of women in geoscience occupations: Geoscience Currents, number 33.

Boykoff, M., 2008, Media and Scientific Communication: A Case of Climate Change, in Liverman, D.G.E., Pereira, C.P., Marker, B. (eds), Communicating Environmental Geoscience, Geological Society of London Special Publication 305, pp. 11-18.

Hartz, J. and Chappell, R. 1998, Worlds Apart: how the distance between science and journalism threatens America's future, First Amendment Center Publication 98-FO2, 178 pages.

Liverman, D.G.E., Pereira C.P., Marker B., 2008, Communicating Environmental Geoscience, Geological Society of London Special Publication 305, 214 pages.

Liverman, D.G.E, 2008, Environmental geoscience - communication challenges, in Liverman, D.G.E., Pereira, C.P., Marker, B. (eds) Communicating Environmental Geoscience, The Geological Society of London Special Publication 305, pp. 197-210.

Liverman, D.G.E. 2010, Communicating geological hazards: educating, training and assisting geoscientists in communication skills, in T. Beer (ed.), Geophysical Hazards, International Year of Planet Earth, Springer Netherlands, pp. 41-55.

Neild ,T., 2008, Altered priorities ahead - or, how to develop fruitful relationships with the media, in Liverman, D.G.E., Pereira, C.P., Marker, B. (eds) Communicating Environmental Geoscience, Geological Society of London Special Publication 305, pp. 5-10.

Peters, H.P., Brossard, D., de Cheveigné, D., Dunwoody, S., Kallfass, M., Miller, S. and Tsuchida, S., 2008, Interactions with the Mass Media, Science, v. 320, p 204

Royal Society, 2006, Survey of factors affecting science communication by scientists and engineers, Royal Society, London, 45 pages.

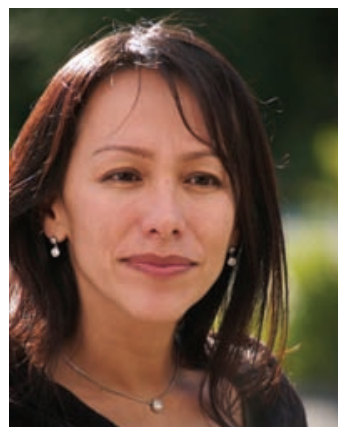

Monica Jaramillo is a geoscientist at British Columbia Hydro and Power Authority (BC Hydro) in Vancouver, Canada. She has worked in the field of geohazards in South America and Canada. Her main interest is risk management through the integration of geohazard information for land use planning, emergency management and decision making processes. She is a member of the IUGS Geoscience for Environmental Management Commission. 